\title{
LA PROTECCIÓN DEL DERECHO A LA SALUD: EL CASO PERUANO
}

\section{THE PROTECTION OF THE RIGHT TO HEALTH: THE PERUVIAN CASE}

\section{Frank García Ascencios ${ }^{1}$}

DOI: https://doi.org/10.37767/2591-3476(2020)18

Fecha de envío: 30.06 .2020

Fecha de aceptación: 21.08 .2020

\section{RESUMEN:}

La protección del derecho a la salud busca hacer efectivo su acceso en condiciones de calidad, oportunidad, disponibilidad y aceptabilidad, tal como consagra el Derecho internacional. En el plano local, en el año 2013, el Perú decide reformular el sistema de protección de salud en beneficio del paciente. Sobre la base de una bibliografía relevante y la experiencia del autor, el artículo reflexiona sobre el actual sistema dirigido por la Superintendencia Nacional de Salud y lo considera un referente en América Latina, pues otorga al Estado la capacidad para sancionar administrativamente cualquier exceso de las empresas prestadoras y financiadoras de salud $y$, al mismo tiempo, provee eficaces espacios alternativos, a la vía judicial, para solucionar cualquier controversia en materia de salud.

\begin{abstract}
The protection of the right to health attempts to make its access effective under conditions of quality, opportunity, availability, and acceptability, as enshrined in International Law. At the local level, in 2013, Peru decided to redesign the health protection system for the benefit of the patient. Based on relevant bibliography and the author's experience, this article reflects on the current system run, by Superintendence National of Health, and considers it a benchmark in Latin America, as it gives the State the ability to administratively sanction any excess by the health providers and financing companies and, at the same time, provides effective alternative channels, other to the judiciary, to solve any controversy in health matters.
\end{abstract}

PALABRAS CLAVE: Constitución; Políticas Públicas; Regulación; Salud; Susalud.

KEY WORDS: Constitution; Health; Public Policy; Regulation; SUSALUD.

1 Abogado y Magíster en Derecho Empresarial por la Universidad de Lima (Perú). LLM en Derecho por la Universidad de Hawaii at Manoa (USA). Máster en Seguros y Gerencia de Riesgos por la Universidad Pontificia de Salamanca (España). Docente universitario en la Universidad de Lima. E-mail: frankgarciaascencios@gmail.com. ORCID iD: https://orcid.org/0000-0002-7117-5727. 


\section{Introducción.}

La salud es un derecho consagrado en diversas Constituciones del mundo ${ }^{2}$, pues goza de protección en el más alto nivel normativo. Asimismo, la salud ha traspasado el reconocimiento constitucional de cada Estado para impregnarse en diversas normas internacionales de protección de los derechos humanos, por lo que hoy es reconocido como un derecho humano.

Resulta irrefutable la preeminencia del derecho a la salud en todo país que considere ser un Estado constitucional. Por ende, el horizonte hacia la protección del derecho a la salud debe generar que cada Estado regule las acciones destinadas a garantizar su acceso, calidad, oportunidad, disponibilidad y aceptabilidad. Para lograr este objetivo, es necesario marchar más allá del reconocimiento constitucional, internacional y jurisprudencial.

A partir de la revisión de las principales normativas internacionales y un examen cuidadoso de la regulación local y políticas públicas específicas de salud en el país, este documento discute la amalgama de los servicios de salud actuales con el derecho a la salud en el Perú. Dado que finalmente la regulación administrativa es tarea de cada Estado y, por ello, acorde a su propia realidad, sin menoscabo de la dignidad del ser humano y de los principios de libre competencia, el artículo presenta un sistema regulatorio, sancionador y mecanismos alternativos de solución de conflictos, apoyado en la experiencia del autor sobre esta materia en particular. La información desplegada en el artículo permite al autor deducir las conclusiones que anota al final del mismo.

\section{El derecho a la salud y su regulación administrativa}

\section{El derecho a la salud}

La salud es un derecho inherente al ser humano. Es un derecho constitucional y un derecho humano. La persona goza del derecho a la salud por su sola condición de ser humano. Si hay un derecho esencial para la supervivencia ese es el derecho a la salud.

El artículo $25^{\circ}$ numeral 1 de la Declaración Universal de los Derechos Humanos regula que: "Toda persona tiene derecho a un nivel de vida adecuado que le asegure, así como a su familia, la salud y en especial la alimentación, el vestido, la vivienda, la asistencia médica y los servicios sociales necesarios; tiene asimismo derecho a los seguros en caso de desempleo, enfermedad, invalidez, viudez, vejez u otros casos de pérdida de sus medios de subsistencia por circunstancias independientes de su voluntad".

El artículo $12^{\circ}$ del Pacto Internacional de Derechos Económicos, Sociales y Culturales recoge que: "1. El derecho de toda persona al disfrute del más alto nivel posible de salud física y mental. 2. Entre las medidas que deberán adoptar los Estados Partes en el Pacto a fin de asegurar la plena efectividad de este derecho, figurarán las necesarias para: a) La reducción de la mortinatalidad y de la mortalidad infantil, y el sano desarrollo de los niños; b) El mejora-

\footnotetext{
2 Por ejemplo, el artículo $7^{\circ}$ de la Constitución del Perú regula que: "Todos tienen derecho a la protección de su salud, la del medio familiar y la de la comunidad así como el deber de contribuir a su promoción y defensa. La persona incapacitada para velar por sí misma a causa de una deficiencia física o mental tiene derecho al respeto de su dignidad y a un régimen legal de protección, atención, readaptación y seguridad".

El artículo $42^{\circ}$ de la Constitución de Argentina recoge que: "Los consumidores y usuarios de bienes y servicios tienen derecho, en la relación de consumo, a la protección de su salud, seguridad e intereses económicos; a una información adecuada y veraz; a la libertad de elección, y a condiciones de trato equitativo y digno".

El artículo $43^{\circ}$ de la Constitución de España señala que: "1. Se reconoce el derecho a la protección de la salud. 2. Compete a los poderes públicos organizar y tutelar la salud pública a través de medidas preventivas y de las prestaciones y servicios necesarios. La ley establecerá los derechos y deberes de todos al respecto. 3. Los poderes públicos fomentarán la educación sanitaria, la educación física y el deporte. Asimismo, facilitarán la adecuada utilización del ocio".
} 
miento en todos sus aspectos de la higiene del trabajo y del medio ambiente; c) La prevención y el tratamiento de las enfermedades epidémicas, endémicas, profesionales y de otra índole, $y$ la lucha contra ellas; d) La creación de condiciones que aseguren a todos asistencia médica y servicios médicos en caso de enfermedad".

El artículo XI de la Declaración Americana de los Derechos y Deberes del Hombre señala que: "Toda persona tiene derecho a que su salud sea preservada por medidas sanitarias y sociales, relativas a la alimentación, el vestido, la vivienda y la asistencia médica, correspondientes al nivel que permitan los recursos públicos y los de la comunidad".

El artículo $10^{\circ}$ del Protocolo Adicional a la Convención Americana sobre Derechos Humanos en materia de Derechos Económicos, Sociales y Culturales recoge que: "1. Toda persona tiene derecho a la salud, entendida como el disfrute del más alto nivel de bienestar físico, mental y social. 2. Con el fin de hacer efectivo el derecho a la salud los Estados partes se comprometen a reconocer la salud como un bien público y particularmente a adoptar las siguientes medidas para garantizar este derecho: a. la atención primaria de la salud, entendiendo como tal la asistencia sanitaria esencial puesta al alcance de todos los individuos y familiares de la comunidad; b. la extensión de los beneficios de los servicios de salud a todos los individuos sujetos a la jurisdicción del Estado; c. la total inmunización contra las principales enfermedades infecciosas; $d$. la prevención y el tratamiento de las enfermedades endémicas, profesionales y de otra índole; e. la educación de la población sobre la prevención y tratamiento de los problemas de salud, y f. la satisfacción de las necesidades de salud de los grupos de más alto riesgo y que por sus condiciones de pobreza sean más vulnerables".

El derecho a la salud es universal, indivisible, integral, irrenunciable e inalienable, inviolable y progresivo. Es universal porque es inherente a todos los seres humanos. Es indivisible porque no puede dividirse, su reconocimiento es sistémico. Es integral porque se vincula con otros derechos como el derecho a la vida, integridad y a la dignidad. Es irrenunciable e inalienable porque es un derecho no objeto de transacción, ni disposición. Es inviolable porque el Estado garantiza su defensa. Es progresivo porque su ámbito de protección es cada vez mayor, no limitante, ni restringido.

La Organización Mundial de la Salud" la define como un "bienestar físico, mental y social y no meramente la ausencia de enfermedad". La salud tiene una concepción amplia, y debe ser interpretada de forma extensiva, no restrictiva. El Estado es responsable de garantizar el pleno acceso a las prestaciones de salud. Esencialmente, la Constitución peruana ${ }^{4}$ y la Ley General de Salud ${ }^{5}$ recogen con claridad este rol del Estado.

Conjuntamente, al reconocimiento en declaraciones, pactos, cartas y convenciones de derechos humanos ${ }^{6}$, El Comité de Derechos Económicos, Sociales y Culturales de las Na-

\footnotetext{
3 Organización Mundial de la Salud. Preguntas más frecuentes. Disponible en: http://www.who.int/suggestions/faq/es/. Fecha de consulta: 27.07.2020.

4 En adición al artículo $7^{\circ}$, los artículos $9^{\circ}, 10^{\circ}$ y $11^{\circ}$ de la Constitución recogen que: “9. El Estado determina la política nacional de salud. El Poder Ejecutivo norma y supervisa su aplicación. Es responsable de diseñarla y conducirla en forma plural y descentralizadora para facilitar a todos el acceso equitativo a los servicios de salud". "10. El Estado reconoce el derecho universal y progresivo de toda persona a la seguridad social, para su protección frente a las contingencias que precise la ley y para la elevación de su calidad de vida". "11 El Estado garantiza el libre acceso a prestaciones de salud y a pensiones, a través de entidades públicas, privadas o mixtas. Supervisa asimismo su eficaz funcionamiento”.

5 El artículo I de la Ley General de Salud, Ley N ${ }^{\circ} 26842$, regula que: "la protección de la salud es de interés público. Por tanto, es responsabilidad del Estado regularla, vigilarla y promoverla".

6 El profesor español Pérez Luño expresa que: "Desde la génesis de los derechos humanos en la modernidad a su actual significación que se desprende de la Declaración de la ONU, la universalidad es un rasgo decisivo para definir a estos derechos. Sin el atributo de la universalidad nos podemos encontrar con derechos de los grupos, de las etnias, de los estamentos, de entes colectivos más o menos numerosos, pero no con derechos humanos. Precisamente
} 
ciones Unidas, en la observación general 14, desarrolla el derecho a la salud reconocido en el Pacto Internacional de Derechos Económicos, Sociales y Culturales, para lo cual considera la presencia de los siguientes elementos: disponibilidad, accesibilidad, aceptabilidad y calidad.

Disponibilidad significa que el Estado debe contar con suficientes establecimientos de salud para la atención de la población; establecimientos que deben tener condiciones adecuadas, agua potable, profesional capacitado y bien remunerado.

Accesibilidad representa que los servicios de salud deben estar al alcance de todos, no discriminándose por ninguna causa. Garantizando que la geografía no sea una limitación para acceder a estos servicios. Asimismo, debe procederse conforme al principio de equidad, para que todos tengan acceso al servicio, sin importar su condición social.

Aceptabilidad significa que los establecimientos respeten la ética médica, la cultura de las personas, minorías y mayorías. Dentro del respeto a la cultura se procura mejorar el estado de salud de las personas.

Calidad representa que los establecimientos de salud deben ser óptimos, al igual que sus bienes y servicios, por lo que debe contarse con profesionales de la salud idóneos, y con medicamentos y equipamiento médico en óptimas condiciones.

El Tribunal Constitucional peruano ha considerado que el Estado debe jugar un rol activo en beneficio del derecho a la salud. Así, enfatiza en que "el Estado debe adoptar todas las medidas posibles para que, bajo los principios de continuidad en la prestación del servicio, eficacia, eficiencia, solidaridad y progresividad, etc., se haga viable su eficacia en la práctica, de manera tal que todas las prestaciones requeridas por una persona en determinada condición de salud sean garantizadas de modo efectivo y eficaz" ${ }^{\prime \prime}$.

El derecho a la salud goza de un contenido principista de profundo alcance. El reconocimiento constitucional y legal exige medidas efectivas y progresivas de cada país para garantizar su protección. En otras palabras, este derecho no puede quedarse en el reconocimiento constitucional o en alguna ley en general, sino debe contar con regulación sectorial.

No hay discusión en que todos buscan un sistema de salud óptimo para su población, porque es un ideal que todos tengan acceso a un sistema sanitario de calidad. Este es un ideal en todo el mundo. Sin embargo, la interrogante es cómo se logra.

La realidad demuestra que incluso los países menos desarrollados, y con un sistema sanitario con carencias, consagran a la salud como un derecho constitucional y humano, pero no cuentan con mecanismos eficaces que garanticen su protección.

\footnotetext{
el gran avance de la modernidad reside en haber formulado la categoría de unos derechos del género humano, para evitar cualquier tipo de limitación o fragmentación en su titularidad. A partir de entonces la titularidad de los derechos, enunciados como derechos humanos, no va a estar restringida a determinadas personas o grupos privilegiados, sino que va a ser reconocida como un atributo básico inherente a todos los hombres, por el mero hecho de su nacimiento". Pérez Luño, A.E. (1998) La Universalidad de los Derechos Humanos. Anuario de Filosofía del Derecho. Disponible en: http://rodare.cl/fda/ unidad-ii/Sobre\%20la\%20Universalidad\%20de\%20los\%20Derechos\%20Humanos.pdf. Fecha de consulta: 27.07.2020.

7 Tribunal Constitucional. (2010) Expediente N03426-2008-HC/TC, fundamento 9. Disponible en: https://www.tc.gob.pe/jurisprudencia/2010/034262008-HC.html. Fecha de consulta: 27.07.2020.
} 


\section{La regulación administrativa}

La función de regular, tradicionalmente, adoptó un rol protagónico del Estado. Éste, por ser titular de los recursos y al contar con calidad gubernamental, debía administrar directamente los servicios públicos. Así, por ejemplo, esta visión clásica ${ }^{8}$ sustenta que los servicios de salud, al ser un servicio público, deben ser administrados exclusivamente por el Estado.

La visión tradicional de la regulación buscó un estado paternalista donde los precios estuvieran controlados por el Estado, por lo que la diferencia de productos, lo que se conoce como calidad, fue perjudicada por la regulación de las etapas de producción de bienes y servicios.

En la segunda parte del siglo XX, la escuela liberal cuestiona severamente este modelo económico considerando este sistema como ineficiente y supresor de la innovación. Por consiguiente, hoy, al menos en el Perú, el Estado no juega un rol de planificador y controlador en la economía, sino garantiza su acceso en condiciones de calidad, para lo cual promueve la protección de los consumidores y la libre competencia en el mercado.

La noción de ser, o no, un Estado planificador y controlador genera debate. Perú ha adoptado el modelo de Economía Social de Mercado, por lo que permite el libre mercado, donde el Estado cumple un rol subsidiario en la economía, que incluso lo restringe de realizar actividades empresariales. Únicamente, por ley expresa y subsidiariamente, lo puede hacer. Esta decisión es adoptada en la Constitución de 1993.

Más allá de la discusión ideológica sobre el particular, estos cambios en el régimen económico permitieron el ascenso económico del Perú en Latinoamérica9

Dentro del marco constitucional, el Estado peruano orienta el desarrollo del país y actúa principalmente solo en las siguientes áreas: promoción de empleo, salud, educación, seguridad, servicios públicos e infraestructura. Se promueve la inversión privada en estas áreas, pero simultáneamente interviene el Estado para garantizar, por ejemplo, el acceso a servicios como agua, luz, telefonía, educación, salud, entre otros.

Con la restricción en la actividad económica del Estado peruano, lo que sí crece es el nivel de regulación de diversas áreas, con el objeto de proteger a los consumidores de abusos por parte de los que realizan actividad económica. La regulación no puede sustituir al mercado debe promover la competencia, el no abuso del mercado y la protección de los consumidores. Esta es una regulación moderna, no planificadora del mercado, sino garantizando el juego limpio de los agentes.

Por consiguiente, el acto de regular es inevitable. Regular servicios públicos como la salud es imprescindible. En estos tiempos de COVID-19, de pandemia, el Estado, excepcionalmente, regula con mayor rigurosidad el acceso a servicios públicos como la salud. Incluso, la Ley General de Salud permite que el Estado disponga de todos los recursos médico-asistenciales de los sectores público y privado existentes en las zonas afectadas y en las colindantes.

8 Perú permite la inversión de empresas privadas en servicios públicos como la salud. No obstante, se reconoce que también existen cuestionamientos sobre la participación del privado en la oferta del servicio de salud.

9 Banco Mundial. (2020) Perú panorama general. Disponible en: https://www.bancomundial.org/es/country/peru/overview. Fecha de consulta: 27.07.2020. 
El fondo del tema es la calidad regulatoria ${ }^{10}$. El rol como regulador del Estado ha generado la creación administrativa de organismos que vigilan la actividad privada y pública en diversos servicios públicos, como la salud.

El supervisor tiene un rol fundamental, debido a que desde su autonomía técnica regula, supervisa, fiscaliza y sanciona en el ámbito administrativo la conducta ilegal del Estado y de los privados respecto a la oferta de servicios públicos a los consumidores.

Simultáneamente, al rol desempeñado por los órganos reguladores o supervisores, el Estado peruano cuenta con un Instituto Nacional de Defensa de la Competencia y de la Protección de la Propiedad Intelectual (INDECOPI), donde una de sus acciones es la vigilancia de la no vulneración o amenaza del derecho de los consumidores.

\section{El Ministerio de Salud}

El Ministerio de Salud (MINSA) es el órgano rector encargado de conducir el Sistema Nacional Coordinado y Descentralizado de Salud peruano. Formula, dirige, ejecuta, supervisa y evalúa las políticas nacionales del sector.

EI MINSA, al ser órgano rector, goza de la función de regular políticas públicas que logren el aseguramiento universal en salud, promoción, prevención, recuperación y rehabilitación de la salud, incrementar la oferta pública y privada del servicio, generar proyectos de infraestructura sanitaria, entre otros.

El rol del MINSA es fundamental al generar políticas públicas. Sin embargo, el funcionamiento del sistema necesita de la interrelación de diversos agentes para que finalmente una persona goce de atención médica. Así, por ejemplo, los establecimientos de salud son prestadores de servicios de salud, pero para acudir a dicho centro debe tenerse la calidad de asegurado, salvo emergencia.

La atención médica no es gratuita, pese al loable reconocimiento constitucional y legal sobre la universalidad del derecho a la salud. En realidad, hay que determinar de dónde proceden los fondos para la atención, de capital público o privado. Sin embargo, resulta irrefutable la carencia de recursos frente a la amplia necesidad de servicios de salud.

Frente a este escenario, el MINSA cumple una labor gerencial. Sin embargo, la experiencia ha enseñado que a pesar de contarse con adecuadas políticas públicas la realidad muestra deficiencias en el sistema, por lo que los reclamos frente a un deficiente servicio de salud son parte ineludible del sistema.

En efecto, al MINSA gozar de una función esencialmente gerencial, entonces la labor de supervisar, fiscalizar y sancionar a los establecimientos y gestores de fondos de salud se encomienda a la Superintendencia Nacional de Salud. SUSALUD es la encargada de promover y proteger los derechos en salud.

10 El profesor Gaspar Ariño afirma que "la regulación tiene que aportar claridad y previsibilidad a la evolución de estos sectores, tiene que facilitar la realización de planes de negocio y promover la inversión en ellos, tiene que definir el "tablero de juego" cara al futuro de una manera clara y estable, en la que los operadores pueden confiar". Ariño Ortiz, G. (2006) Logros y fracasos de la regulación. Themis Nº 52, Revista de Derecho. 


\section{La Superintendencia Nacional de Salud y la Protección del Derecho a la Salud}

\section{SUSALUD}

SUSALUD es el órgano técnico adscrito al Ministerio de Salud responsable de promover y proteger los derechos en salud. Es el órgano que vela por la materialización del acceso a los servicios de salud, con calidad, disponibilidad y aceptabilidad. SUSALUD está en la primera línea de batalla, es decir, busca hacer realidad el derecho a la salud.

Con el objeto de proteger el derecho a la salud, SUSALUD regula, supervisa, fiscaliza y sanciona a las Instituciones Administradoras de Fondos de Aseguramiento en Salud (IAFAS), Instituciones Prestadoras de Servicios de Salud (IPRESS) y Unidades de Gestión de IPRESS (UGIPRESS). Las IAFAS ${ }^{11}$ son entidades públicas o privadas que captan, reciben y/o gestionan fondos para la atención o cobertura de salud. Las IPRESS son los establecimientos públicos y privados de salud, hospitales y clínicas. Las UGIPRESS son las unidades gestoras de los establecimientos salud.

SUSALUD enmarca sus competencias en el D.L. N ${ }^{\circ} 1158$, norma madre de la Superintendencia. No obstante, tiene su origen en la denominada Superintendencia de Entidades Prestadoras de Salud (SEPS), organismo que autorizó, reguló y supervisó a las entidades prestadoras de salud (EPS), conforme a las prerrogativas de la Ley $N^{\circ} 26790$. Posteriormente, con la Ley Marco del Aseguramiento Universal en Salud, aprobada por la Ley N²9344, la SEPS se convierte en la Superintendencia Nacional de Aseguramiento en Salud (SUNASA), que supervisó IAFAS e IPRESS, pero no gozó de potestad sancionadora establecida por ley.

En el año 2013, el Gobierno promueve una reforma en el sector salud, donde una de las principales reformas es garantizar la protección del derecho a la salud. En ese sentido, es emitido el DL. N ${ }^{\circ} 1158$, norma que convierte a la SUNASA en SUSALUD. SUSALUD sí posee rol de regulador, supervisor, fiscalizador y sancionador de IAFAS, IPRESS y UGIPRESS.

SUSALUD es un ente administrativo orientado centralmente en los siguientes aspectos: a) Promoción y defensa de los derechos en salud; b) Regulación de las IAFAS, IPRESS y UGIPRESS; c) Supervisión y sanciones administrativas.

La creación de SUSALUD, como ente administrativo, genera controversia, debido a la sobre regulación, supervisión, fiscalización y sanción, pues en el medio también existen otras instituciones que gozan de estas funciones, como INDECOPI, la Superintendencia de Banca, Seguros y AFP (SBS) y el MINSA.

INDECOPI perdería su competencia para conocer y resolver casos vinculados a servicios de consumo de salud y cobertura médica, según el DL № 1158 y el D.S. № 026-2015-SA, reglamento de transferencia de funciones INDECOPI a SUSALUD.

SBS mantiene la facultad de regulación de las compañías aseguradoras que ofertan cobertura de salud. Sin embargo, su rol es disímil al de SUSALUD, debido a que se enfoca en su regulación como aseguradora, mientras que SUSALUD centra su atención a los asegurados o beneficiarios de los seguros de salud, cuando alegan vulneración a sus derechos como usuarios del servicio, es decir, en la cobertura ofrecida por la aseguradora.

11 Por ejemplo, son IAFAS: Seguro Integral de Salud, Seguro Social de Salud, Fondo Intangible Solidario de Salud, Fondos de Aseguramiento en Salud de las Fuerzas Armadas y la Policía Nacional del Perú, Entidades Prestadoras de Salud, Empresas aseguradoras que ofertan cobertura de salud, entre otras. 
Asimismo, SUSALUD cuenta con la competencia para identificar cláusulas abusivas en los contratos y convenios, con excepción de las pólizas de salud, que son supervisadas por la SBS. Sin embargo, SUSALUD, en cada procedimiento sancionador, puede inaplicar la cuestionada cláusula abusiva.

En efecto, el sistema peruano es sui generis porque en relación con las compañías aseguradoras existen dos órganos reguladores, supervisores y sancionadores, SBS y SUSALUD. Éste último solo interviene por la denuncia de un asegurado respecto a conflictos sobre la cobertura médica ofertada, sea por la cobertura del seguro de salud, o por las prestaciones médicas del Seguro Complementario de Trabajo de Riesgo (SCTR), o las atenciones médicas del Seguro Obligatorio contra Accidentes de Tránsito (SOAT), o de la Asociación de Fondos Regionales o Provinciales contra Accidentes de Tránsito (AFOCAT).

Finalmente, SUSALUD es un órgano técnico especializado adscrito al MINSA, pero goza de autonomía técnica, funcional, administrativa, económica y financiera. El MINSA regula la categorización de los establecimientos salud, es decir, el nivel de funcionamiento autorizado para que una clínica ofrezca sus servicios. SUSALUD se encarga de supervisar que los establecimientos categorizados cumplan con los requisitos de su categorización, es decir, SUSALUD realiza acciones orientadas a garantizar la atención sanitaria con calidad a los pacientes.

\section{La Protección del Derecho a la Salud}

La protección del derecho a la salud goza de desarrollo normativo en el Perú. La Ley $N^{\circ}$ 29414 y el DS. N 027-2015-SA regulan los derechos de las personas usuarias de los servicios en salud. La norma tiene en cinco pilares: a) Derecho al acceso a los servicios de salud, b) Derecho al acceso a la información, c) Derecho a la atención y recuperación de la salud, d) Derecho al consentimiento informado; $y$, e) Derecho a la protección de los derechos.

El reconocimiento de los derechos del paciente es un hito en la historia, debido a que contiene principios cardinales del respeto al derecho de los usuarios del servicio de salud, es decir, concretiza la protección de derechos implícitos en el derecho a la salud. Así, se reconoce derechos primordiales como el ser informado sobre el estado de salud, respetar la privacidad y el derecho a brindar el consentimiento frente a tratamientos médicos. Inclusive, en una revolución de la forma de resolver los conflictos, se apuesta por los Mecanismos Alternativos de Solución de Controversias (MARCS o ADR) para la resolución de los conflictos.

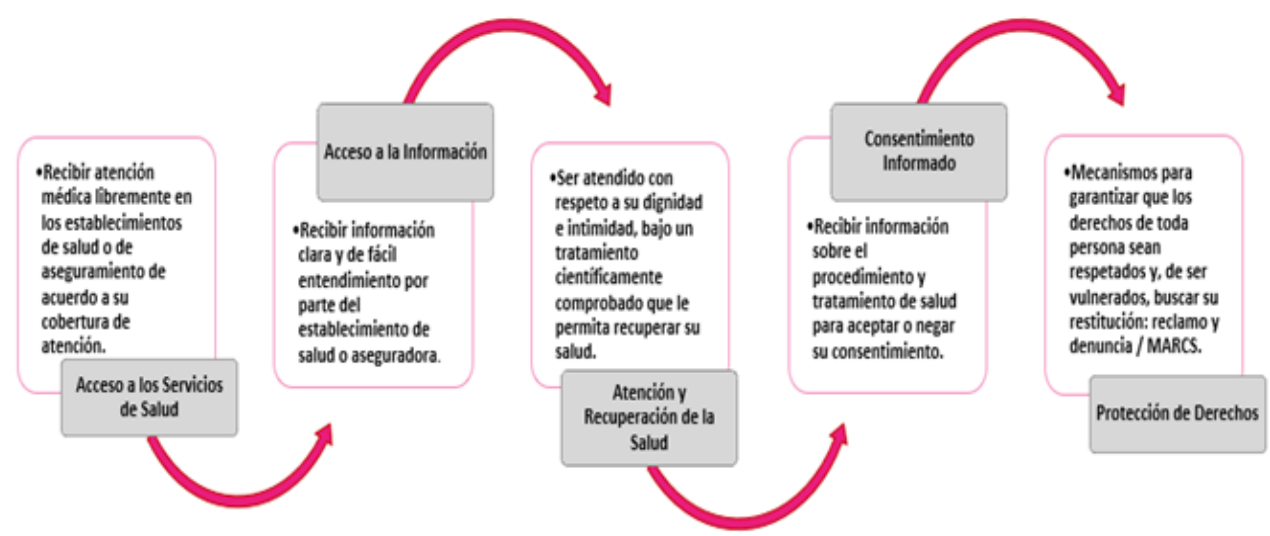

Fuente: Superintendencia Nacional de Salud 
El legislador busca la efectividad de estos derechos, por lo que denomina a SUSALUD como órgano encargado de velar por el cumplimiento de esta normativa. SUSALUD emite normas orientadas en lograr su finalidad: la protección de la salud. SUSALUD realiza labores de supervisión y/o fiscalización para prevenir futuras acciones que vulneren la salud. SUSALUD ejerce la potestad sancionadora sobre organizaciones por la violación del derecho a la salud. Finalmente, fomenta y gestiona los MARCS para la solución de conflictos.

El usuario tiene la posibilidad de formular denuncia administrativa contra la organización que afecta sus derechos en salud. Asimismo, tiene el derecho de contar con vías alternativas, a la vía judicial, para resolver sus conflictos, y contar con una solución célere y especializada. A continuación, se desarrolla la potestad sancionadora de SUSALUD y los MARCS en salud. Ambas se enmarcan con el objeto de lograr la protección de los derechos.

\subsection{Potestad sancionadora}

SUSALUD cuenta con la potestad para sancionar a IAFAS, IPRESS y UGIPRESS cuando por acción u omisión se afecta el derecho a la salud, como la información, cobertura, los estándares de acceso, calidad, oportunidad, disponibilidad y aceptabilidad.

La potestad sancionadora es definida como "el poder que posee la Administración Pública para castigar a los administrados, cuando estos lesionan determinados bienes jurídicos reconocidos por el marco constitucional y legal vigente. Esta potestad, mediante la represión de ciertas conductas, busca incentivar el respeto y cumplimiento del ordenamiento jurídico, desincentivando la realización de infracciones"m2.

SUSALUD adquiere legalmente la potestad sancionadora del D.L. N 1158; norma con rango de ley que faculta a imponer sanciones dependiendo de su gravedad: leves, graves y muy graves. Puede establecerse sanciones desde la amonestación escrita, multa hasta quinientas (500) Unidades Impositivas Tributarias (UIT) ${ }^{13}$, suspensión, restricción de servicios, cierre temporal, revocación de autorizaciones de funcionamiento de IAFAS y cierre definitivo de IPRESS.

El procedimiento administrativo sancionador o trilateral sancionador que inicia SUSALUD debe seguir los principios mínimos garantizados para el procedimiento sancionador. La Ley N²7444 enumera las garantías que toda Entidad está obligada a cumplir al iniciar, tramitar y resolver un sancionador contra los administrados. Es imprescindible resguardar el debido procedimiento (debido proceso), pues SUSALUD ha de emitir decisiones administrativas que perjudicará a los administrados.

Algunas garantías mínimas del debido procedimiento son: principio de legalidad, debido procedimiento, razonabilidad, tipicidad, irretroactividad, concurso de infracciones, continuidad de infracciones, causalidad, principio de licitud, culpabilidad y non bis in idem. Legalidad porque la facultad para ejercer potestad sancionadora debe fijarse por ley 0 normas con rango de ley. Debido procedimiento porque el órgano que instruye debe ser distinto al órgano que resuelve, esto garantiza la imparcialidad de lo resuelto en instancia administrativa.

12 Vergaray Béjar, V y Gómez Apac, H. (2006) La potestad sancionadora y los principios del procedimiento sancionador. En: Maraví, M. Sobre la Ley del Procedimiento Administrativo General. UPC.

13 Aproximadamente hasta S/ 2'100,000 (Dos Millones Cien Mil con 00/100 Soles) o su equivalente de \$ 615,000 (Seiscientos Quince mil con 00/100 Dólares). 
Razonabilidad porque debe considerarse determinados elementos objetivos ${ }^{14}$ para graduar la sanción. Tipicidad porque la conducta debe estar plasmada como infracción. Irretroactividad porque no puede sancionarse al amparo de una norma no vigente al momento de la comisión de la infracción, salvo beneficie al administrado. Concurso de infracciones porque cuando haya más de una conducta, se aplica la sanción de mayor gravedad. Continuidad de infracciones porque determina la procedencia de la sanción en caso existir prolongación de su comisión, dentro de garantías.

Causalidad porque la sanción recae exclusivamente contra quien omite o realiza la infracción. Principio de licitud porque se presume que los administrados procedieron conforme a ley. Culpabilidad porque la responsabilidad administrativa es subjetiva, no objetiva, salvo ley o decreto legislativo que disponga lo contrario. Non bis in idem porque no puede imponerse doble sanción por casos donde se observe identidad de sujeto, hecho y fundamento.

Por consiguiente, SUSALUD procede conforme el respeto irrestricto de estas garantías administrativas, es decir, la posibilidad de imponer sanciones a IPRESS, IAFAS y UGIPRESS debe enmarcarse en el respeto irrestricto del debido procedimiento. A continuación, desarrollamos el procedimiento llevado a cabo por SUSALUD para lograr brindar una protección efectiva al derecho a la salud.

En caso de insatisfacción del servicio, el usuario puede formular directamente su reclamo contra la IPRESS, IAFAS y UGIPRESS. Estas organizaciones cuentan hasta con treinta (30) hábiles para la atención del reclamo. El sistema incentiva el trato directo (negociación) entre el usuario afectado por la atención médica o cobertura y el establecimiento salud o la financiadora del servicio. Asimismo, el usuario afectado puede recurrir a los centros de conciliación, mediación y arbitraje, para la resolución de los conflictos.

El sistema fomenta la protección del derecho a la salud porque crea un libro de reclamaciones en salud; cuaderno de obligatoria exhibición por parte de las IPRESS, IAFAS y UGIPRESS, por lo que cualquier usuario podrá formular su reclamo directamente en el libro. De igual modo, existe una exigencia legal para exhibir los derechos y obligaciones de los pacientes, para conocimiento de las personas en general. Incluso, el sistema obliga a contar con la Plataforma de Asistencia al Usuario en Salud (PAUS) para la atención de consultas y reclamos de los usuarios.

En caso el usuario no quede satisfecho por la respuesta a su reclamo, posterior o simultáneamente, puede formular denuncia acudiendo a SUSALUD. La Intendencia de Protección de Derechos en Salud (IPROT) es la dependencia donde se presenta las denuncias. IPROT recaba la documentación necesaria para emitir un informe de intervención, es decir, realiza una labor de investigación sobre el hecho denunciado por el usuario.

IPROT tiene un rol fundamental debido a que es la cara visible de SUSALUD, es la dependencia que está en la primera línea de batalla para lograr una efectiva protección de la salud. El informe de intervención de IPROT puede culminar con la derivación de la

14 La Entidad debe evaluar la razonabilidad de la sanción, por lo que considera los siguientes elementos antes de sancionar: a) Beneficio ilícito resultante por la comisión de la infracción; b) Probabilidad de detección de la infracción; c) Gravedad del daño al interés público y/o bien jurídico protegido; d) Perjuicio económico causado; e) Reincidencia, por la comisión de la misma infracción dentro del plazo de un (1) año desde que quedó firme la resolución que sancionó la primera infracción; f) Circunstancias de la comisión de la infracción; y g) Existencia o no de intencionalidad en la conducta del infractor. 
denuncia a la Intendencia de Fiscalización y Sanción (IFIS), que es finalmente la dependencia que decide el inicio del procedimiento administrativo sancionar en contra de las IPRESS, IAFAS Y UGIPRESS.

IFIS es el órgano instructor del procedimiento administrativo sancionador, éste es el encargado de iniciar y conducir el procedimiento, que recomienda la imposición, o no, de sanciones. La Superintendencia Adjunta de Regulación y Fiscalización (SAREFIS) es el órgano decisor en primera instancia administrativa. SAREFIS recibe el informe final de instrucción de IFIS y convoca a vista de la causa, sesión donde el administrado tiene la posibilidad de brindar sus alegatos orales, luego SAREFIS resuelve el caso.

Desde el inicio del procedimiento sancionar, IFIS puede solicitar a SAREFIS el otorgamiento de medidas preventivas, es decir, cautelares al constatarse la verosimilitud de la vulneración del derecho a la salud y el peligro en la demora del procedimiento que puede causar un daño irreparable, entonces es factible concederse medida preventiva mientras se lleve a cabo el procedimiento.

SAREFIS, conjuntamente a la sanción, dicta medidas correctivas destinadas a corregir o revertir la conducta infractora, en protección del usuario y del sistema en salud. Las medidas correctivas no tienen naturaleza sancionadora. Entre las medidas que pueden imponerse están: devolver cobros indebidos o en exceso, atender la solicitud de información, declarar inexigible las cláusulas de los contratos que sean abusivas, publicación de avisos rectificatorios o informativos y someter a la IAFA a un régimen de vigilancia.

El Tribunal de SUSALUD es el órgano administrativo que conoce y resuelve en segunda instancia administrativa los recursos impugnatorios. El Tribunal es integrado por vocales no funcionarios de SUSALUD, por lo que garantiza una visión integral al resolver el conflicto. Asimismo, el Tribunal puede fijar precedentes vinculantes respecto a la interpretación de normas vinculadas a SUSALUD. La decisión del Tribunal agota la instancia administrativa.

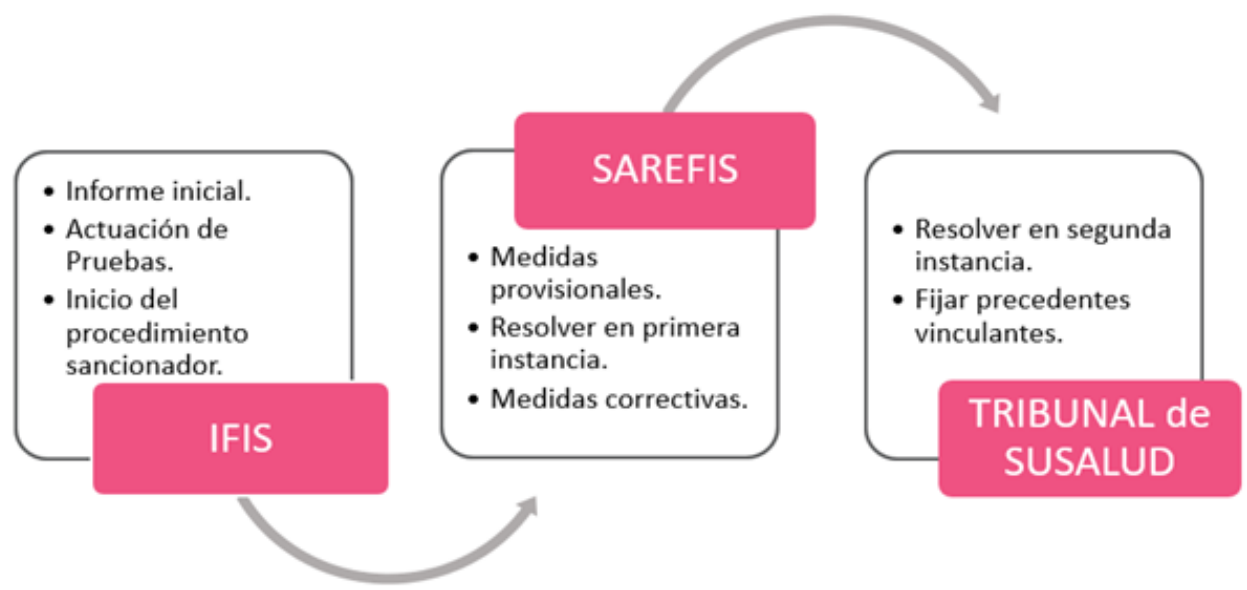

Fuente: Superintendencia Nacional de Salud 
El ejercicio de la potestad sancionadora culmina con la imposición, o no, de sanciones. En consecuencia, la responsabilidad administrativa, en contra de IPRESS, IAFAS y UGIPRESS, corresponde ser ejercida por SUSALUD, con el único objeto de lograr se brinde acceso a los servicios de salud con calidad, oportunidad, disponibilidad y aceptabilidad.

En adición a la función que cumple SUSALUD para la protección del derecho a la salud, también ha incentivado el uso de MARCS para brindar una alternativa de solución al usuario. Los MARCS cumplen un rol notable en la protección de derechos.

\subsection{Mecanismos Alternativos de Solución de Conflictos.}

Los MARCS o los Alternative Dispute Resolution (ADR) son mecanismos alternativos, a la vía judicial, de solución de conflictos. Buscan que no se acuda al litigio judicial, sino que solucionen sus conflictos a través de medios "alternativos", ajenos, al aparato estatal de justicia.

Tradicionalmente, los MARCS son los siguiente: negociación, mediación, conciliación y arbitraje. La negociación es iniciada voluntariamente en la búsqueda de una solución armoniosa, sin necesidad de contar con la presencia de un mediador o conciliador. En otras palabras, las propias partes directamente conversan para resolver el conflicto que surge entre ambas. SUSALUD incentiva el trato directo con el paciente. La ventaja que tienen las IAFAS, IPRESS y UGIPRESS es que resuelven el conflicto directamente sin acudir al regulador.

La mediación es el mecanismo por el cual un tercero, mediador, promueve el dialogo entre las partes, quienes pueden arribar, o no, a un acuerdo. La mediación es un mecanismo flexible donde no existen un procedimiento previamente determinado por ley, por lo que tiene bondades para resolver los casos sensibles sobre la atención o cobertura médica.

La conciliación es un procedimiento que promueve el dialogo voluntario para arribar a un acuerdo. En el Perú se emplea la conciliación administrativa y la extrajudicial. En la primera el procedimiento conciliatorio es regulada por cada Entidad. En contraste, en la segunda el Ministerio de Justicia y Derechos Humanos (MINJUSH) es el que regula el procedimiento conciliatorio. El centro de conciliación extrajudicial tiene la obligación de cumplir con este procedimiento conciliatorio. Sobre el particular, las conciliaciones especializadas en salud se brindan en el marco de la conciliación extrajudicial.

El arbitraje es un medio alternativo de solución de conflictos donde las partes deciden no acudir al sistema judicial de justicia y eligen a un tercero, tribunal arbitral colegiado o unipersonal, para que de forma independiente e imparcial resuelva el conflicto mediante un laudo arbitral, de carácter inapelable.

El Centro de Conciliación y Arbitraje (CECONAR) es el órgano que gestiona los MARCS especializados en salud. EI CECONAR lleva a cabo mediaciones, conciliaciones y arbitrajes, con el objeto de ofrecer un medio alternativo especializado y célere de solución de conflictos. CECONAR realiza conciliaciones extrajudiciales, por lo que está supeditado a la regulación del MINJUSDH sobre materia conciliatoria. Asimismo, administra con autonomía técnica los arbitrajes especializados en salud.

CECONAR cumple un rol acorde a la protección de los derechos en salud, debido a que la 
Ley $\mathrm{N}^{\circ} 29414^{15}$, Ley que establece los derechos de las Personas Usuarias de Los Servicios de Salud, y su reglamento, DS. N ${ }^{\circ}$ 027-2015-SA ${ }^{16}$, garantizan el acceso al paciente de "mecanismos de acceso a la justicia a las personas que consideren haber sido vulnerados en sus derechos, sin que la capacidad económica de las personas sea un limitante para garantizar su acceso oportuno e independiente".

CECONAR es un centro público de conciliación y arbitraje. El rol desempeñado es trascendente dentro del sistema, debido a que es un órgano que efectiviza la cultura de paz frente a los conflictos. Adicionalmente, al rol de ser un centro público, el DL N 1158 le otorga nuevas competencias. Así, debe cumplir con el rol de administrar a nivel nacional el servicio de conciliación y arbitraje en materia de salud, a través del registro y habilitación de centros de conciliación y arbitraje.

Sobre el particular, se considera que la labor regulatoria debe ejercitarse con cautela, sobre todo cuando abordamos los MARCS que por esencia son flexibles y de naturaleza voluntaria, y donde el MINJUSDH juega un rol protagónico. Es muy probable que estas nuevas competencias no lleguen a ser efectivas, porque es difícil encontrar una justificación para una sobrerregulación. De igual manera, al no otorgarle al CECONAR la potestad sancionadora, nada podría hacer para que los agentes cumplan con sus obligaciones, solo se tendría estos registros como referenciales, sin facultad para poder supervisar, fiscalizar, ni sancionar.

La función del CECONAR debe continuar en seguir desempeñándose como un centro que realiza mediaciones, conciliaciones extrajudiciales y arbitrajes, en beneficio del sistema, y dotando de mecanismos alternos de solución de conflictos, para la protección del derecho a la salud en el país.

\section{Colofón}

Debido a las complejidades de los regímenes socioeconómicos, la protección del derecho a la salud es un constante desafío para todo Estado que se precie en cumplir las normativas internacionales y locales. Asimismo, dado que el principal centro de protección es el asegurado o paciente del servicio de salud, los Estados no deben pasar por alto el irrestricto respeto por las garantías esenciales de tal proceso. En ese marco, el Perú ha realizado avances significativos en la creación de todo un sistema administrativo, a fin de lograr efectivizar el acceso al derecho a salud de calidad.

Este marco legal posibilita al Estado la potestad de sancionar administrativamente todo exceso en las prácticas realizadas por las instituciones prestadoras y aseguradoras de fondos de salud, en cualquier modalidad: IAFAS, IPRESS o UGIPRESS. Además, paralelamente, se provee mecanismos alternativos de resolución de conflictos, con la ventaja efectiva de tiempo y todo tipo de costes. No obstante, el sistema adoptado aún cuenta con deficiencias, debido a la diversificación de los servicios de salud a través de distintas

\footnotetext{
$15 \mathrm{El}$ artículo $15.3^{\circ}$ literal f) de la Ley No 29414 regula que: "A ser escuchada y recibir respuesta por la instancia correspondiente cuando se encuentre disconforme con la atención recibida, para estos efectos la Ley proveerá de mecanismos alternativos y previos al proceso judicial para la solución de conflictos en los servicios de salud".

$16 \mathrm{El}$ artículo $29^{\circ}$ del DS. No 027-2015 recoge que: "En caso de surgir controversias entre las IAFAS, IPRESS o UGIPRESS y la persona usuaria de los servicios de salud, aquellas deberán generar mecanismos ágiles y oportunos de solución mediante el trato directo o el uso de mecanismos alternativos de solución de controversias, sin perjuicio del acceso a la vía jurisdiccional. En caso las partes hayan acordado el sometimiento a arbitraje y no alcancen un acuerdo sobre el centro competente, se entenderá como centro competente el Centro de Conciliación y Arbitraje de SUSALUD. SUSALUD propiciará mecanismos de acceso a la justicia a las personas que consideren haber sido vulnerados en sus derechos, sin que la capacidad económica de las personas sea un limitante para garantizar su acceso oportuno e independiente".
} 
instituciones públicas y la ausencia a nivel nacional de SUSALUD, institución que carece de presencia nacional, pues solo figura en la capital y en la zona norte del país. Es urgente la unificación del sistema y una real inversión pública con eficiencia en SUSALUD.

Con el objeto de haber aportado en la difusión y reflexión sobre del sistema de protección a la salud peruano, se concluye estas líneas.

\section{REFERENCIAS BIBLIOGRÁFICAS}

- Ariño Ortiz, G. (2006) Logros y fracasos de la regulación. Themis N²52, Revista de Derecho.

- Banco Mundial. (2020) Perú panorama general. Disponible en: https://www.bancomundial.org/es/country/peru/overview. Fecha de consulta: 27.07.2020

- Bello Janeiro, D. (2011) La responsabilidad médica. Pontificia Universidad Javeriana Bogotá.

- Constitución de la Nación Argentina. Disponible en: http://servicios.infoleg.gob.ar/infolegInternet/anexos/0-4999/804/norma.htm. Fecha de consulta: 27.07.2020

- Constitución Española. Disponible en: https://www.senado.es/web/conocersenado/ normas/constitucion/index.html. Fecha de consulta: 27.07.2020

- Constitución Política del Perú. Disponible en: http://www.pcm.gob.pe/wp-content/ uploads/2013/09/Constitucion-Pol\%C3\%ADtica-del-Peru-1993.pdf. Fecha de consulta: 27.07.2020

- Declaración Americana de los Derechos y Deberes del Hombre. Disponible en: https:// www.oas.org/dil/esp/Declaraci\%C3\%B3n_Americana_de_los_Derechos_y_Deberes_del_ Hombre_1948.pdf. Fecha de consulta: 27.07.2020

- Declaración Universal de los Derechos Humanos. Disponible en: https://www.un.org/ es/universal-declaration-human-rights/\#: :text=La\%20Declaraci\%C3\%B3n\%20Universal\%20de\%20los, historia\%20de\%20los\%20derechos\%20humanos.\&text=La\%20 Declaraci\%C3\%B3n\%20establece\%2C\%20por\%20primera,a\%20m\%C3\%A1s\%20de\%20 500\%20idiomas.. Fecha de consulta: 27.07.2020

- Ley General de Salud, Ley No 26842. Disponible en: https://www.gob.pe/institucion/ minsa/normas-legales/256661-26842. Fecha de consulta: 27.07.2020

- Ley que establece los derechos de las personas usuarias de los servicios de salud, Ley No 29414. Disponible en: http://www.leyes.congreso.gob.pe/Documentos/Leyes/29414. pdf. Fecha de consulta: 27.07.2020

- Reglamento de la Ley $N^{\circ} 29414$, Ley que establece los derechos de las personas usuarias de los servicios de salud, D.S N 027-2015-SA. Disponible en: https://elperuano.pe/ normaselperuano/2015/08/13/1273843-3.html. Fecha de consulta: 27.07.2020

- Organización Mundial de la Salud. Preguntas más frecuentes. Disponible en: http:// www.who.int/suggestions/faq/es/. Fecha de consulta: 27.07.2020

- Pacto Internacional de Derechos Económicos, Sociales y Culturales. Disponible en: https://www.ohchr.org/SP/ProfessionalInterest/Pages/CESCR.aspx. Fecha de consulta: 27.07.2020

- Pérez Luño, A.E. (1998) La Universalidad de los Derechos Humanos. Anuario de Filosofía del Derecho. Disponible en: http://rodare.cl/fda/unidad-ii/Sobre\%20la\%20Universalidad\%20de\%20los\%20Derechos\%20Humanos.pdf. Fecha de consulta: 27.07.2020 
- Protocolo Adicional a la Convención Americana sobre Derechos Humanos. Disponible en: http://derechoshumanos.pe/wp-content/woo_uploads/congreso/PROTOCOLO_SAN_ SALVADOR.pdf. Fecha de consulta: 27.07.2020

- Superintendencia Nacional de Salud. Disponible en: http://portal.susalud.gob.pe/. Fecha de consulta: 27.07 .2020

- Tribunal Constitucional. (2010) Expediente N03426-2008-HC/TC, fundamento 9. Disponible en: https://www.tc.gob.pe/jurisprudencia/2010/03426-2008-HC.html. Fecha de consulta: 27.07 .2020

- United States Agency International Development (USAID PERÚ) y Asociación Peruana de Derecho Sanitario (APDS). (2005) Guía de Capacitación. Derechos de las personas usuarias y resolución de conflictos en los servicios de salud.

- Velásquez, A, Suarez, D y Nepo-Linares, E. (2016) Reforma del sector salud en el Perú: derecho, gobernanza, cobertura universal y respuesta contra riesgos sanitarios. En Revista Peruana de Medicina Experimental y Salud Pública. Disponible en: https://rpmesp. ins.gob.pe/index.php/rpmesp/article/view/2338/2313. Fecha de consulta: 27.07.2020

- Vergaray Béjar, V y Gómez Apac, H. (2006) La potestad sancionadora y los principios del procedimiento sancionador. En: Maraví, M. Sobre la Ley del Procedimiento Administrativo General. UPC. 